\title{
Arc discharge and electrode phenomena
}

\author{
Masao Ushio \\ Welding Research Institute, Osaka University \\ Mihogaoka, Ibaraki, Osaka 567, Japan
}

\begin{abstract}
Some distinctive features of arc electrode phenomena are briefly reviewed and a comparative study on tungsten-oxide electrode is presented showing the superior characteristics of $\mathrm{La}_{2} \mathrm{O}_{3}-\mathrm{W}, \mathrm{CeO}_{2}-\mathrm{W}$ and $\mathrm{Y}_{2} \mathrm{O}_{3}-\mathrm{W}$ electrodes, compared with $\mathrm{ThO}_{2}-\mathrm{W}$.
\end{abstract}

\section{INTRODUCTION}

Arc discharge is the most convenient method to generate the thermal plasma, which is characterized by the high energy content and the local thermal equilibrium state (ITE). The arc discharge has been utilized in a variety of devices such as arc lamp, welding machine, gas heater, chemical reactor, arc furnace, plasma spray equipment and so on.

The arc consists of three major parts, as shown in Fig. 1, the arc column, the cathode region and the anode region. The arc column has the charge equilibrium, the low electric field and high temperature, so that it plays fundamental role in heating the gas. While the cathode and anode regions, where the transition between metalic and gaseous condition occurs, have positive and negative space charges with high electric field respectively, and also have high temperature gradient.

The arc is self-sustained discharge between two electrodes, which has a voltage drop at the cathode of the order of minimum ionizing or minimum exciting potential of the gas or vapor, and capability to support large current by providing its own mechanism of electron emission from negative electrode (ref. 1). The electrode region has the key role to ensure the above mechanism and therefore the so-called electrode phenomena has the decisive effect on arc stability and discharge behavior. The purpose of this paper is to present briefly the recent development and application of arc electrode and related phenomena.

\section{THERMODYNAMICS AND NON-THERMIONIC CATHODES}

Prof. A. E. Guile summarized the arc electrode phenomena in his laborious review and characterized the electrode region as follows (ref. 2);

a) High electric and thermal field,

b) Contraction : High current density relative to those of arc column (Table 1). It also causes the strong pumping of plasma gas stream directed axially away from the electrode reaching $10^{2}-10^{3} \mathrm{~m} / \mathrm{s}$ in velocity.

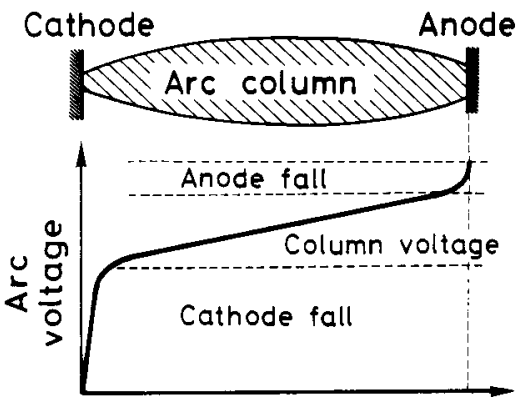

Table 1. Characteristics of electrode current density

\begin{tabular}{lll}
\hline Non-thermionic arc cathode & $10^{10-12}$ & $\mathrm{~A} / \mathrm{m}^{2}$ \\
Thermionic arc cathode & $10^{6}-8$ & \\
Glow discharge cathode & $10^{6}-7$ (1 atm) \\
Arc anode & $10^{6}-9$ & \\
Arc plasma column & $10^{5}-7$ & \\
\hline
\end{tabular}

Fig. 1 Arc voltage distribution 
Arc cathode should be the electron emitter, and the condition is set up by the action of arc itself. And also, in low pressure atmosphere, a sufficient vapor must be supplied from electrode in order to maintain the arc discharge.

When the negative electrode is heated up to a sufficient high temperature, electrons are emitted with a current density J given by the RichardsonDushman equation,

$$
J=A T^{2} \exp (-e \psi / k T)
$$

where, $A=6 \times 10^{5} \mathrm{~A} / \mathrm{m}^{2} \mathrm{~K}^{2}, \psi$; thermionic work function, $e$; electron charge, $\mathrm{k}$; Boltzman constant, and $\mathrm{T}$; temperature in Kelvin.

If the simple thermionic emission can explain the current density at the arc cathode surface of the order shown in Table 1, it should be called as the thermionic cathode. These current densities on tungsten are in the range $106-10^{8} \mathrm{~A} / \mathrm{m}^{2}$, and when it is emitting thermionically, the cathode occupies a fixed position and operates very stably. Boiling points and thermionic work function of various materials are plotted in Fig. 2 , with a superposition of three different curves representing thermionic cathode current densities. Refractory metals like tungsten can be the thermionic cathode, but low boiling point metal such as $\mathrm{Ni}, \mathrm{Fe}$ and $\mathrm{Al}$ can not be the thermionic cathode.

In the case of non-thermionic materials, the mechanism of electron emission must be considered without the thermionic emission. However, it is not clear yet. Temperature-aided field emission is seemed to be the leading theory (ref. 3).

Non-thermionic cathode consists of many cathode spots, in general. The spot is so small that the current density is extremely high, and it moves rapidly with intense visible traces on electrode surface. Since the current is concentrated at those spots, the electrode material is moved away from the spots as metal vapor jet. The spot normally consists at any instant of a number of small emitting sites, which share the current at $0.1-100 \mathrm{~A}$ per site.

At low pressure environment, these spots become metal vapor source to sustain the arc discharge and appears even in case of refractory metal cathode. This phenomenon has been applied to the ion-plating technique in vacuum arc. If the reactive gas is used as environment the reactive vacuum arc deposition is obtainable.

\section{THERMIONIC TUNGSTEN CATHODE}

As thermionic cathode the sintered tungsten electrode containing ThO 2 (2\%) has been widely used. However, it has not always satisfactory properties in arc stability and electrode durability. Particularly, the change in tip shape due to melting and consumption in long term arc burning is a serious problem.

In order to develop more durable tungsten electrode, various types of tungsten-oxide electrode were produced and compared in the operational characteristics, namely, arc starting properties, arc voltage-current relationship, arc stability, electrode tip temperature, consumption and deformation of tip due to heavy current loading, effect of oxygen introduced into inert gas atmosphere on the characteristics of electrode (ref. 4).

Electrodes in Table 2 were produced by a conventional powder metallurgy process and evaluated with the above mentioned characteristics under the condition : D.C. electrode-negative polarity, $24 \mathrm{~mm}$ in extension length and water cooled copper anode.

Figure 3 shows the appearance of electrode tip after one-hour burning at $180 \mathrm{~A}$ with $1.6 \mathrm{~mm}$, in diameter, electrode (heavy loading). Metallurgical structure is also shown in $\mathrm{Fig.4}$. Electrode containing $\mathrm{La}_{2} \mathrm{O}_{3}$ showed the least change in shape and structure. $\mathrm{Y}_{2} \mathrm{O}_{3}-\mathrm{W}$ and $\mathrm{CeO}_{2}-\mathrm{W}$ were also little molten. On the otherhand, $\mathrm{ThO}_{2}-\mathrm{W}$ has a large melting and production of many holes. $\mathrm{ZrO}_{2}-\mathrm{W}$ has severe consumption at the tip. Pure-W and MgO-W displayed both serious melting. These differences are closely related with the cathode tip temperature, shown in Table 2, which was measured spectroscopically without the effect of arc radiation. 


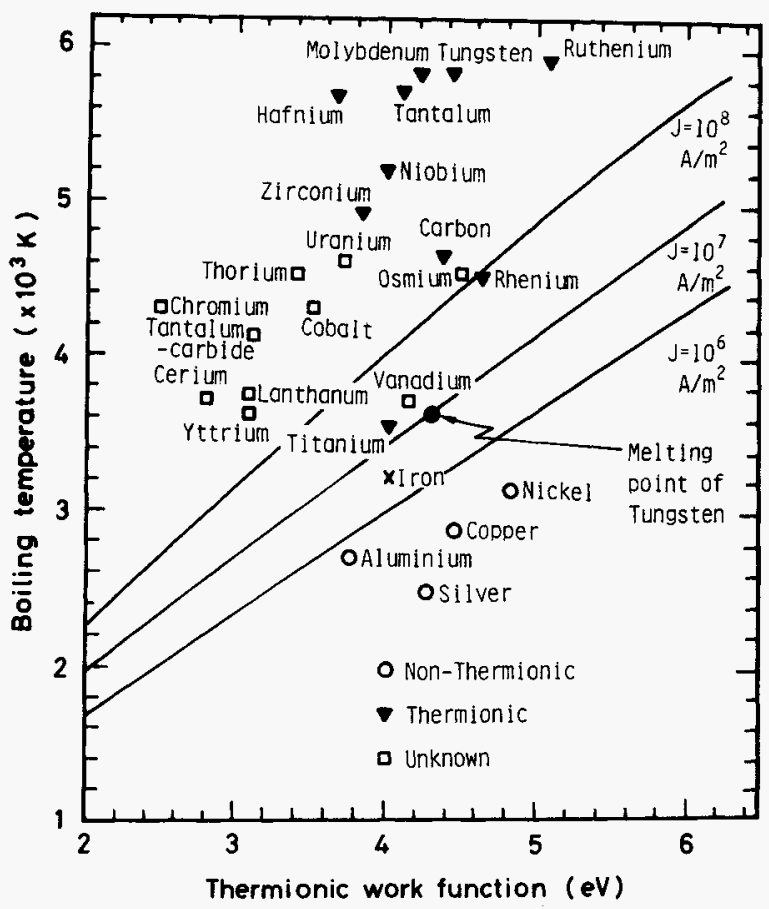

Fig. 2 Temperature for thermionic emission at various current density levels. Individual point shows thermionic work function and boiling point of element.
Electrode diameter $1.6 \mathrm{~mm}$
Arc current $180 \mathrm{~A}$
Operating time $3600 \mathrm{sec}$

Pure-W $\mathrm{ZrO}_{2}(2 \%)-W$ $\mathrm{ThO}_{2}(2 \%)-\mathrm{W}$
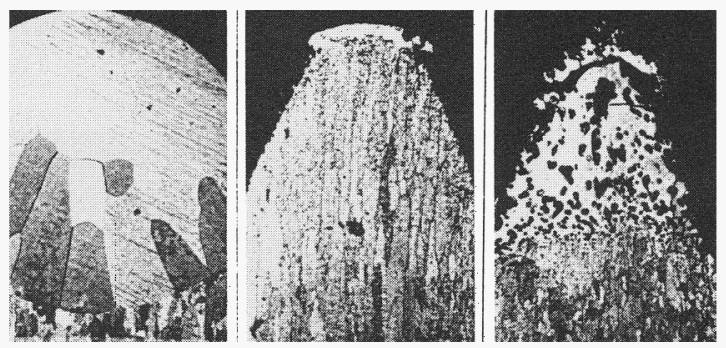

$$
\mathrm{Y}_{2} \mathrm{O}_{3}(2 \%)-\mathrm{W}
$$

$$
\mathrm{La}_{2} \mathrm{O}_{3}(2 \%)-\mathrm{W}
$$

\section{$\mathrm{CeO}_{2}(2 \%)-W$}
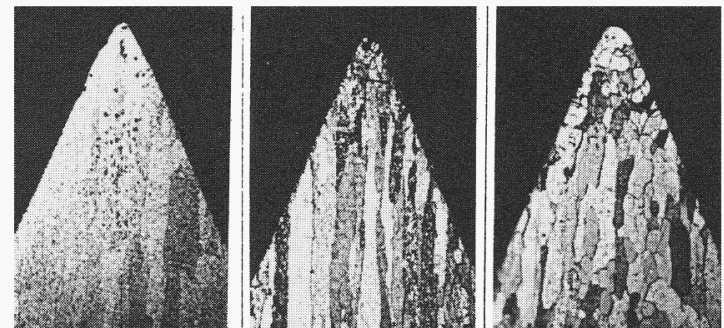

$0.5 \mathrm{~mm}$

Fig. 4 Change in microstructure of electrode cross-section after heavy loading.

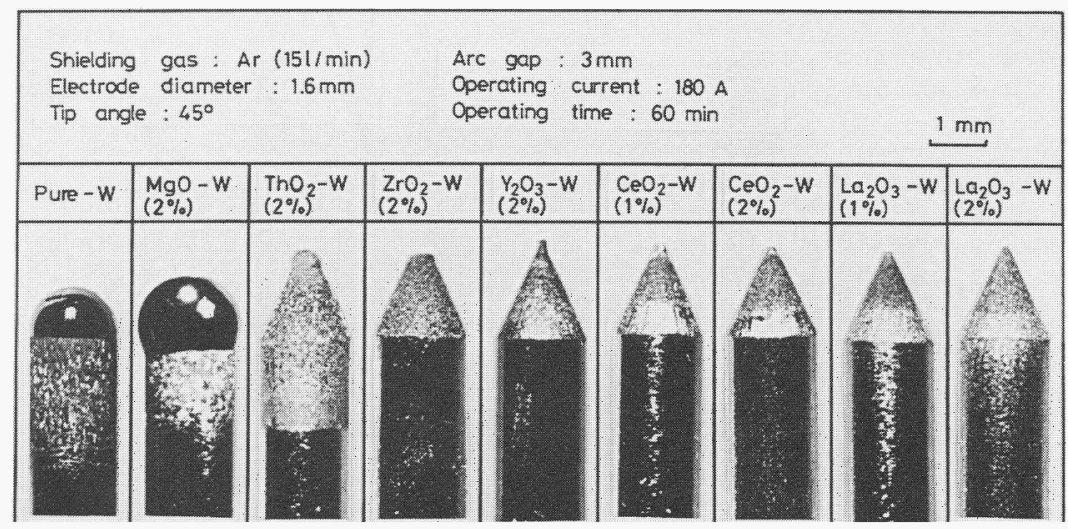

Fig.3 Appearance of electrode tip after long term arc burning with high current density in argon.

Table 2. Tungsten electrode produced and tip temperature

\begin{tabular}{lcc}
\hline Electrode & Oxide content $(\mathrm{s})$ & Tip temperature $(\mathrm{K})$ \\
\hline Pure $-\mathrm{W}$ & & \\
$\mathrm{MgO}-\mathrm{W}$ & 2 & \\
$\mathrm{ZrO}_{2}-\mathrm{W}$ & 2 & $3200-3500$ \\
$\mathrm{ThO}_{2}-\mathrm{W}$ & 2 & $2900-3200$ \\
$\mathrm{La}_{2} \mathrm{O}_{3}-\mathrm{W}$ & 2 & $3100-3300$ \\
$\mathrm{Y}_{2} \mathrm{O}_{3}-\mathrm{W}$ & 2 & $2900-3200$ \\
$\mathrm{CeO}_{2}-\mathrm{W}$ & 2 & \\
\hline
\end{tabular}

Arc burning condition : $200 \mathrm{~A}$, in $\mathrm{Ar}, 3.2 \mathrm{~mm} \phi, 45$ degree tip angle, measurement : $500 \mathrm{~nm}$ and $700 \mathrm{~nm}$ color temperature 


\author{
$\mathrm{CeO}_{2}(1 \%)-W$ \\ Shielding gas : Pure Ar \\ Arc current : $200 \mathrm{~A}$ \\ Operation time : \\ $600 \mathrm{sec}$
}

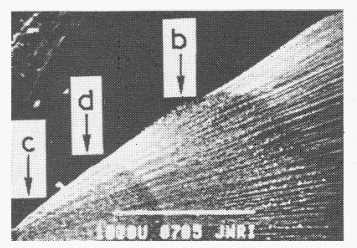

(a)

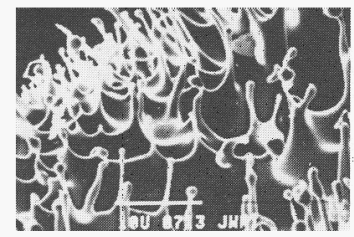

(c)

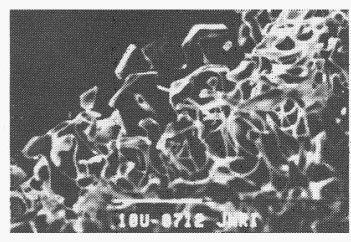

(d)

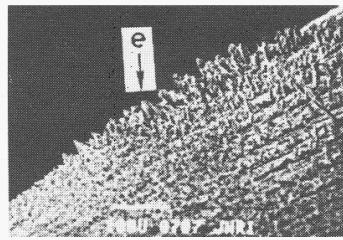

(b)

Fig. 5 Microstructure of electrode tip surface after heavy loading.

Observation of cathode tip surface showed the melting of very thin layer of the tip surface and the growth of tungsten dendrite at the periphery just behind the cathode area after heavy loading, as shown in Fig. 5.

A simple measurement of electrode consumption in steady state manifested the tungsten-oxide electrode has very little consumption, compared with pure-W. However, the tungsten consumption increases extremely with increasing the content of oxygen in the gas atmosphere, while nitrogen and hydrogen have no effect on it, which is shown in Fig. 6

The introduction of oxygen into inert gas atmosphere also promote strongly the growth of tungsten dendrite and resulted in shaping the "rim", like the brim of the hat as shown in Fig. 7 .

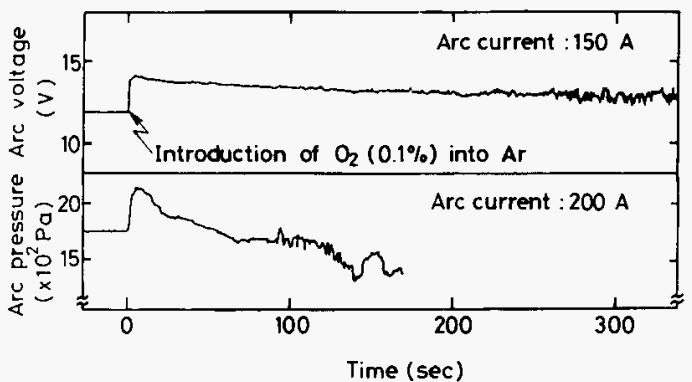

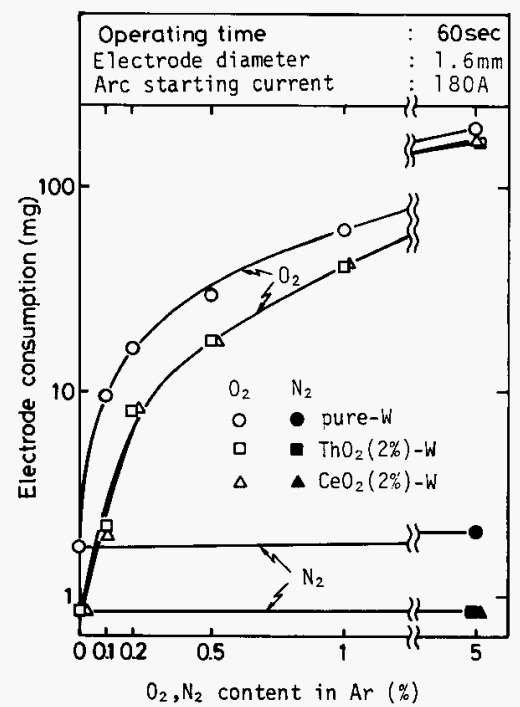

Fig. 6 Effect of oxygen and nitrogen introduced into argon gas on consumption of tungstenoxide electrode.

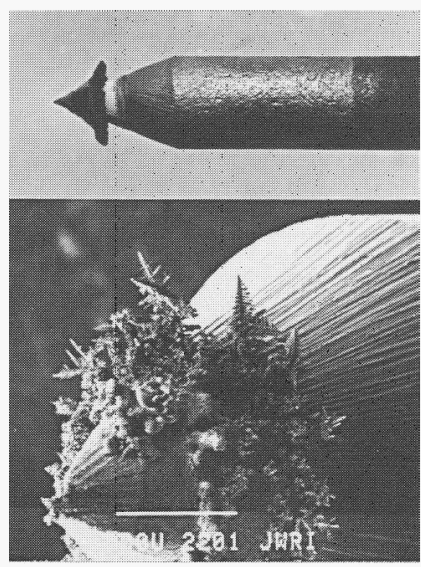

Fig. 7 Unstable arc behavior due to rim formation and appearances of the rim. 
The rim formation changes the arc configuration and causes arc instability. It shows the unstable arc behavior such as in arc voltage and arc pressure at very short time from the instance of introducing oxygen into argon gas, as shown in Fig. 7. The unstable behavior is caused by the rise-up of the rim and its asymmetry of obstacle for plasma gas flow near the cathode.

Oxidized tungsten like $\mathrm{WO}_{3}$ can sublimate intensely at comparatively low temperature. The vapor of oxidized tungsten may decompose and deposit on the surface where the temperature is matched for deposition rather than for melting or sublimating.

\section{ANODE ELECTRODE PHENOMENA}

At the anode, the situation differs strikingly. Anode operates as the electron collector either in an evaporating or cold mode depending on the discharge and electrode conditions.

The total energy transfered to the anode is

$$
Q_{i}=J\left(\mathrm{~V}_{\mathrm{a}}+\Psi+(5 / 2) k \mathrm{~T}_{\mathrm{e}}\right)+Q(\mathrm{R})+\mathrm{Q}(\mathrm{h})
$$

where, $J$ : current density, $V_{a}$ : anode fall voltage, $\Psi$ : work function of anode, (5/2)kTe : electron enthalpy impinging to anode, $Q(R)$ : net input by radiation, $Q(h)$ : heat transfered by gas enthalpy flow.

The temperature of the anode will then rise to a steady level at a rate depending upon the thermal properties and size of the anode and current value. With increasing current, and/or with decrease in thermal diffusivity, it is possible for the anode surface temperature to reach evaporation point within a given duration (ref. 5).

The two most common anode mode are a low current density mode where the anode is essentially passive, acting only as electron collector, and a high current density mode with a fully developed anode spot. These two modes can be observed distinctively in the vacuum arc. The anode spot has a temperature near atmospheric boiling point of the anode material and looks like a copious source of vapor and energetic ions.

The anode region has a steep temperature gradient and in which the thermodynamical state is far from the equilibrium (ref. 6). Ionization, recombination, decomposition and other chemical reaction may occur in the thin boundary layer and its vicinity, also at the anode surface. The physics of this region is not clearly understood yet, as well as that of cathode region, due to the difficulty in obtaining sufficiently accurate data in complex and very small volume.

Recently, Dr. M. Uda found very strong evaporation from molten anode metal in a stationary Gas-Tungsten-Arc with Ar-H2 mixed gas and utilized it to produce the ultra-fine particles of metal (ref. 7). He pointed out the extremely excess absorption of hydrogen atom has an important role to generate the fine particle through bubbling of molecular hydrogen and projecting it away from molten pool. When the hydrogen is replaced by the nitrogen, the major part of obtained particle becomes larger, in diameter, of above $10 \mu \mathrm{m}$, without introducing surface reactive element to reduce the surface tension of molten pool metal (ref. 8).

It is noted that the arc discharge in low pressure atmosphere has characteristically interesting properties. From the point of anode phenomena, it will accerelate the anode mechanism to a fully evaporative and reactive state. It is applied to refine molten iron alloy with effective removing $\mathrm{Cu}, \mathrm{Sn}, \mathrm{C}$ and $\mathrm{N}$ in laboratory scale (ref. 9).

\section{CONCLUSIONS}

A brief review of electrode phenomena in high current arc discharge were presented.

Recent development on thermionic tungsten cathode revealed that the tungstenoxide cathode containing lanthanum-oxide, yttrium-oxide or cerium-oxide has the superior durability compared with the thoriated tungsten. However, 
the tungsten electrode is very weak durability in oxidizing atmosphere, and therefore, introducing oxidizing gas in cathode area makes the arc unstable, due to high consumption and shaping the rim.

On the anode region, two operational modes were simply described. And some applications of anode surface chemistry were presented.

\section{REFERENCES}

1. J. M. Lafferty (ed.), Vacuum arcs, Theory and application, p. v, Wiley (1980).

2. A. E. Guile, Proc. IEE, IEE Reviews 118, 1131-1154(1971).

3. G. Ecker, IEEE Trans., Plasma Science PS-4, 218-227(1976).

4. F. Matsuda, M. Ushio and T. Kumagai, Trans. JWRI 15, 13-19(1986).

5. H. Edels, Proc. 11th Int. Conf. Ionized Gases (Czeckslovakia), 9-59(1977).

6. J. V. Herberline and E. Pfender, IEEE Trans., Plasma Science PS-5, $171-180(1977)$.

7. M. Uda, Bulletin of The JIM 22, 412 (1983) (in Japanese).

8. K. Takeda, Private communication.

9. T. Matsuo, J. ISIJ 71, S136(1985). 